(2) Open Access Full Text Article

LETTER

\title{
Letter to the editor: naltrexone sustained- release/bupropion sustained-release for the management of obesity: review of the data to date
}

This article was published in the following Dove Press journal:

Drug Design, Development and Therapy

8 January 2015

Number of times this article has been viewed

\section{Anna M Buehler}

Hospital Alemao Oswaldo Cruz, Institute of Health Education and Sciences, Sao Paulo, Brazil
Correspondence: Anna M Buehler Hospital Alemao Oswaldo Cruz, Institute of Health Education and Sciences, Rua João Juliao, 245, First floor, 01323-903,

Sao Paulo, SP, Brazil

Tel +55 II 35490582

Email abuehler@haoc.com.br

\section{Dear editor}

I read with great interest the systematic review by Caixàs et $\mathrm{al}^{1}$ on the effect of naltrexone sustained-release/bupropion sustained-release (NB) for the management of obesity. By comprehensively appraising five recent clinical trials, the authors concluded that the naltrexone/bupropion combination might represent an important new therapeutic option for the management of obesity, with a weight reduction effect that is similar to other drugs approved for the treatment of obesity.

In this respect, it is worth highlighting that shortly after the publication of this systematic review (on September 10, 2014), the United States Food and Drug Administration licensed the NB Contrave ${ }^{\circledR}$ medication as an adjunct to a reduced-calorie diet and increased physical activity for chronic weight management in obese or overweight patients with at least one weight-related comorbid condition.

Together, both pieces of information may represent a remarkable advance in the pharmacological treatment of obesity, since the therapeutic arsenal for obesity is limited, with suboptimal efficacy and safety concerns. ${ }^{2,3}$

Despite the promising results reported by Caixàs et a ${ }^{1}$ the accumulated evidence on the efficacy of the NB combination for obesity has some limitations that should be acknowledged. According to the authors' introduction, lower doses of multiple agents targeting different mechanisms of action often yield better results than strategies that modify one pathway alone, especially when we consider the diabetic population. According to this assertion, NB medication would be expected to work better in the diabetic population. With unfortunate timing, the effect of the NB combination was also investigated exclusively in overweight/obese type 2 diabetes patients (CORDiabetes Study Group) in another trial, ${ }^{4}$ which was not included in the systematic review by Caixàs et al. ${ }^{1}$

In this Phase III trial, 505 overweight and obese patients with type 2 diabetes, using or not using background oral antidiabetes drugs, received a standardized lifestyle intervention and were randomized 2:1 to $32 \mathrm{mg}$ naltrexone sustained-release/360 mg bupropion for 56 weeks in a double-blind, placebo controlled fashion.

The treatment protocol and the coprimary outcome were the same as those used by the other three Phase III trials described in detail by Caixàs et al. ${ }^{1}$ When we analyzed the results in the diabetic population, diabetic patients taking NB had a greater weight reduction $(-5.0 \%$ versus $-1.8 \% ; P<0.001)$ and a higher proportion of patients achieving $\geq 5 \%$ weight loss $(44.5 \%$ versus $18.9 \% ; P<0.001){ }^{4}$ 


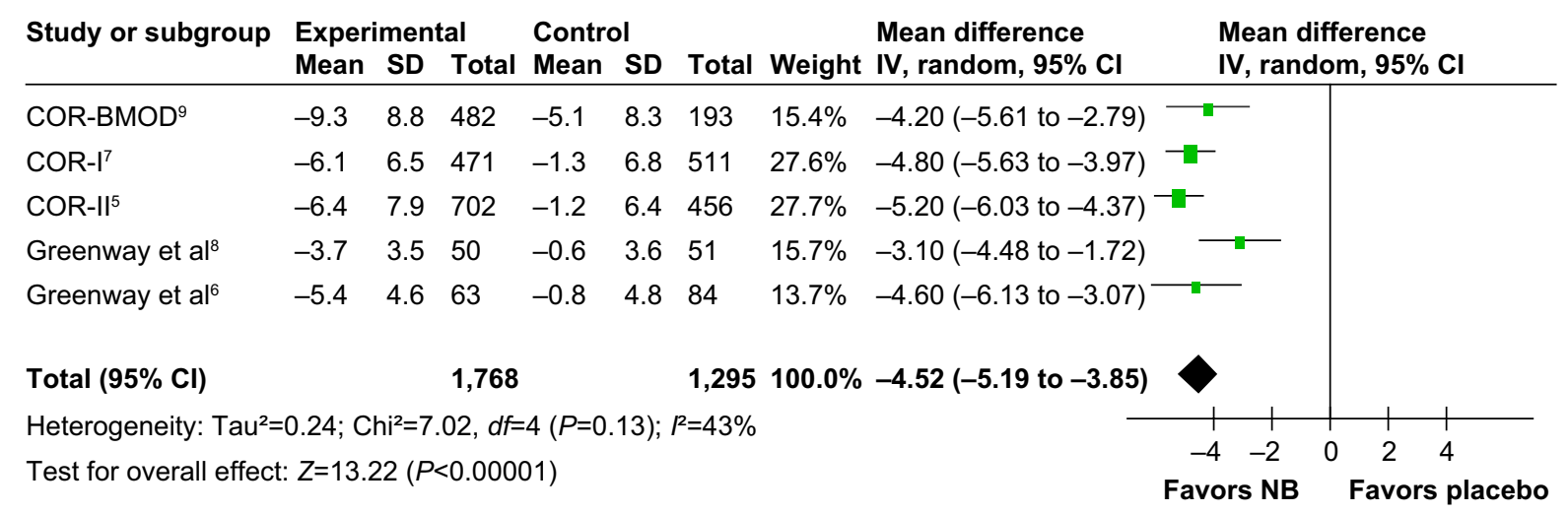

Figure I Meta-analysis of the mean difference of the percentage change in body weight.

Abbreviations: SD, standard deviation; IV, inverse variance; Cl, confidence interval; $d f$, degrees of freedom; NB, naltrexone sustained-release/bupropion sustained-release.

To better compare the magnitude of the effect of NB on diabetic patients to nondiabetics patients, I first metaanalyzed the estimates of the effect of NB for the nondiabetic population, while considering the results of the five studies previously included in the systematic review by Caixàs et al. ${ }^{5-9}$ To do this, I used a random effects model, as well as the absolute mean difference (MD) and risk ratio (RR) as effect sizes for continuous and proportion data, respectively. Further, I did not consider the results of groups of patients assigned to naltrexone or bupropion as monotherapy (when reported by trials with three or more arms); I also considered the results of the groups using more similar Contrave ${ }^{\circledR}$ licensed doses in the longer period of treatment, as assessed by the trial.

The studies defined the primary population for the analyses as "modified intention to treat population last observation carried forward" (mITT-LOCF), which included all randomized participants with a baseline measurement of body weight and $\mathrm{a} \geq 1$ postbaseline measurement of weight, which was obtained while on the study drug. Additionally, for individual missing data, the authors used the last observation carried forward method, which repeats the last observation data obtained while participants were taking the study drug.

The pooled results, totaling 3,063 mITT-LOCF nondiabetic patients, found a reduction of $4.52 \%$ (95\% confidence interval [CI]: -5.19 to $-3.85 ; I^{2}=43 \%$ ) in body weight in the NB group when compared to the placebo group (Figure 1). This percentage of weight loss was greater than that in the COR-Diabetes trial, ${ }^{4}$ which found a reduction of $3.20 \%$ ( $95 \%$ CI: -4.18 to -2.22 ; a total of 424 patients) in patients taking the NB medication when compared to those in the placebo group.

Considering the same primary population (mITT-LOCF; a total of 3,063 patients), patients treated with the NB were 2.54 times (95\% CI: $\left.1.84-3.38 ; P^{2}=49 \%\right)$ more likely to lose at least $5 \%$ of their body weight compared to those on placebo (Figure2).

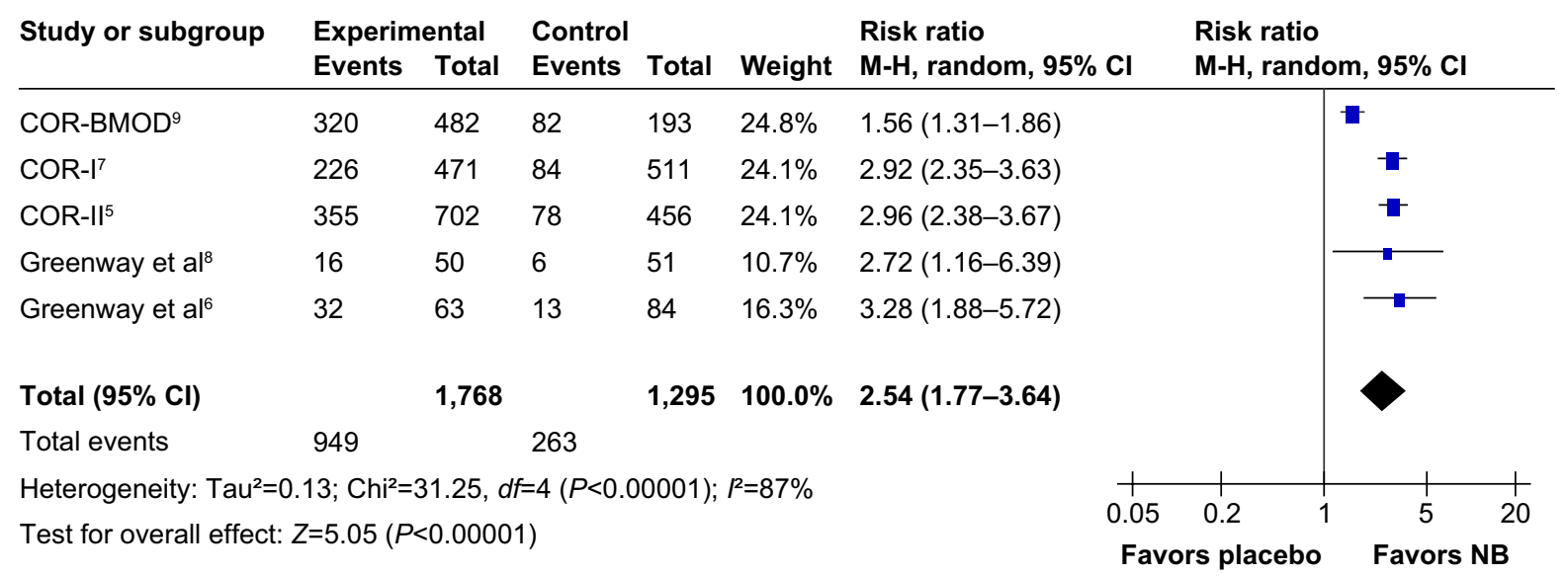

Figure 2 Meta-analysis of the relative risk of the proportion of patients with at least $5 \%$ weight loss.

Abbreviations: $\mathrm{M}-\mathrm{H}$, Mantel-Haenszel; Cl, confidence interval; $\mathrm{df}$, degrees of freedom; NB, naltrexone sustained-release/bupropion sustained-release. 
For the diabetic population, patients treated with the NB were 2.36 times (95\% CI: 1.66-3.35) more likely to lose at least $5 \%$ of their body weight when compared to those on placebo.

These findings are important because the smaller magnitude of the effect of NB in diabetic patients is not expected, and it is not in agreement with the results found in the literature when we consider the use of other antiobesity drugs. The study of Gray et $\mathrm{al}^{2}$ compared orlistat, sibutramine, and other interventions, such rimonabant, in a single-evidence synthesis framework using a systematic review and a mixed treatment comparison approach. In this study, the authors showed that patients with type 2 diabetes treated with antiobesity medications lost more weight in each intervention investigated when compared to those without the disease.

According to the authors of the COR-Diabetes trial, ${ }^{4}$ the somewhat more modest weight loss they observed in patients with diabetes that were taking oral antidiabetes drugs, as compared with patients without diabetes, may be related to the differences in insulin resistance, adipose cell metabolism, and concomitant medications used for the treatment of diabetes and glucose metabolism.

Beyond these conflicting findings, the profile of the patients in the COR-Diabetes trial ${ }^{4}$ differs from that of the other NB studies; the trial included older patients (mean, 54 years versus a range of 40.2-45.9 years in the other trials), a greater proportion of females, and more comorbidities (a greater percentage of patients with dyslipidemia). This finding could suggest a subgroup efficacy effect, which needs to be better investigated.

Another important aspect not addressed in the study by Caixàs et $\mathrm{al}^{1}$ was the risk of bias in the trials. Using the
Cochrane criteria for the risk of bias of randomized controlled trials, ${ }^{10}$ there were no important limitations with respect to randomization, allocation concealment, and blinding scheme domains, despite the fact that in the two Phase II trials, the risk of bias for randomization and allocation concealment were unclear. However, there is a high risk of bias due to the "incomplete outcome data" domain, considering that the primary efficacy analyses were done using an mITT-LOCF population with a significant loss to follow-up/withdrawal, especially in the treatment group (which ranged from 18.4\% to $29.9 \%$ ). The studies also showed a high risk of bias due to the presence of conflicts of interest.

Despite that Caixàs et $\mathrm{al}^{1}$ reported the more conservative estimates of effect size, showing the results for the intention to treat (ITT) population whenever possible, it is important to demonstrate the impact of this bias on the results. Excluding data from the COR-Diabetes trial, ${ }^{4}$ which included a very different population profile, I performed a subgroup metaanalysis comparing the data for both the primary efficacy analyses population (modified ITT population [mITT]) and the ITT population, which were reported by three of the five trials as part of a sensitivity analysis. ${ }^{5,7,9}$ For the percentage change in body weight (Figure 3), there was a significant difference in the subgroup estimates of the effect according to the type of analysis performed. The results for the mITT population showed a greater effect magnitude than those for the ITT population (mITT MD: $-4.52 \%$ [95\% CI: -5.19 to $\left.-3.85 ; I^{2}=43 \%\right]$ versus ITT MD: $-3.33[95 \%$ CI: -3.83 to $-2.82 ; P^{2}=0 \%$ ]; $P$-value for the subgroup $=0.003$ ). For the proportion of patients who lost at least $5 \%$ of their body weight (Figure 4), the difference according to the type of analysis was not significant between the groups, despite

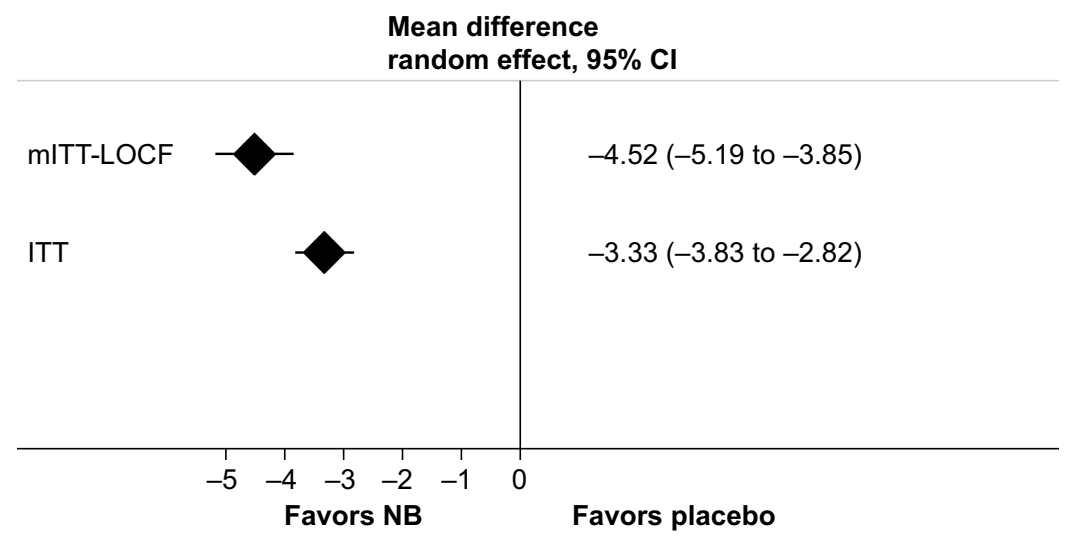

Figure 3 Subgroup analyses - percentage change from baseline in body weight.

Abbreviations: $\mathrm{Cl}$, confidence interval; mITT-LOCF, modified intention to treat population last observation carried forward; ITT, intention to treat; NB, naltrexone sustained-release/bupropion sustained-release. 


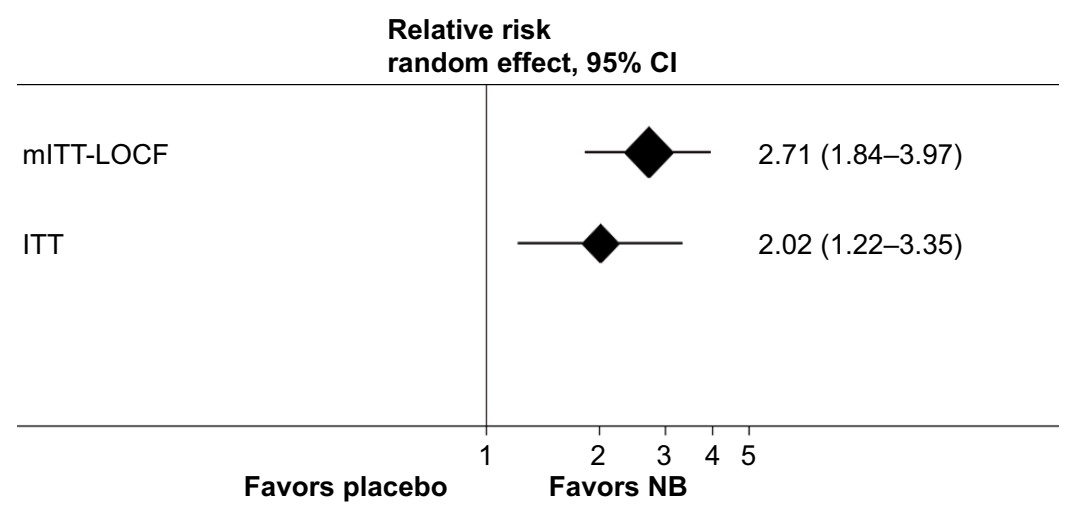

Figure 4 Subgroup analyses - relative risk of the loss of at least $5 \%$ of one's body weight.

Abbreviations: $\mathrm{Cl}$, confidence interval; mITT-LOCF, modified intention to treat population last observation carried forward; ITT, intention to treat; NB, naltrexone sustained-release/bupropion sustained-release.

the effect magnitude being greater in the mITT group than in the ITT population (mITT RR: 2.71 [95\% CI: 1.84-3.99; $\left.I^{2}=89 \%\right]$ versus ITT RR: 2.02 [95\% CI: $\left.1.22-3.35 ; I^{2}=93 \%\right]$; $P$-value for the subgroup $=0.37$ ).

Considering that the participants who were not on treatment were not included in the primary analyses, and since the percentage of excluded patients was much greater in the treatment group, these findings may suggest an overestimated effect of the intervention based on a primary efficacy analysis (mITT-LOCF population). Further, in this analysis, the most exacerbated effects came from small Phase II trials, which are known to overestimate the effects of medical interventions. ${ }^{11}$

Finally, although the profile of adverse reactions to NB was mild, the medication was not well tolerated, since almost three times as many patients discontinued the treatment, according to the pooled estimates of the effect across the trials. Table 1 shows the pooled results for all adverse reactions reported by the six trials. NB significantly increased the risk of all the events reported. Also, it is important to note that the sample included in these analyses was not the same sample included in the efficacy analyses. The safety sample included all randomized participants who took $\geq 1$ pill of the study drug and had $\geq 1$ follow-up visit at any time after the start of the study treatment, which does not necessarily mean that the patients were still on the drug treatment. In this regard, we could not exclude an underestimated effect of NB on the risk of adverse reactions.

\section{Conclusion}

In conclusion, these findings are in accordance with the review's conclusions, given that the current evidence on the effect of the combination of buproprion plus naltrexone indicates that it has a moderate effect on body weight. The information in this letter provides more precise estimates of the efficacy and safety of the NB medication obtained through a meta-analytic approach, with emphasis on the critical appraisal of the studies through the assessment of the risk of bias and its impact on the results. This complements the information reported by the review's authors, and hopefully further helps the reader to draw a better and more critical conclusion about the data that have recently become available.

Table I Meta-analyses of the reported adverse reactions across the studies

\begin{tabular}{|c|c|c|c|c|c|}
\hline Outcome & Studies & $\begin{array}{l}\text { Total number } \\
\text { of participants }\end{array}$ & Statistical method & Effect estimate & $I^{2}(\%)$ \\
\hline Participants reporting any adverse event $\mathrm{t}^{4,5,7,8}$ & 4 & 3,232 & Risk ratio $(\mathrm{M}-\mathrm{H}$, fixed, $95 \% \mathrm{Cl})$ & $1.16(1.12,1.21)$ & 70 \\
\hline Adverse events resulting in discontinuation ${ }^{4,5,8,9}$ & 4 & 2,874 & Risk ratio $(\mathrm{M}-\mathrm{H}$, fixed, $95 \% \mathrm{Cl})$ & $2.83(2.11,3.80)$ & 60 \\
\hline Nausea $^{4-9}$ & 6 & 4,164 & Risk ratio $(\mathrm{M}-\mathrm{H}$, fixed, $95 \% \mathrm{Cl})$ & $3.83(3.24,4.54)$ & 87 \\
\hline Vomiting ${ }^{4-9}$ & 6 & 4,164 & Risk ratio $(\mathrm{M}-\mathrm{H}$, fixed, $95 \% \mathrm{Cl})$ & $3.72(2.77,5.01)$ & 57 \\
\hline Dry mouth ${ }^{4-9}$ & 6 & 4,164 & Risk ratio $(\mathrm{M}-\mathrm{H}$, fixed, $95 \% \mathrm{Cl})$ & $3.21(2.27,4.55)$ & 0 \\
\hline Constipation $^{4-7,9}$ & 5 & 4,061 & Risk ratio $(\mathrm{M}-\mathrm{H}$, fixed, $95 \% \mathrm{Cl})$ & $2.43(1.99,2.96)$ & 28 \\
\hline Headache ${ }^{4-9}$ & 6 & 4,164 & Risk ratio $(\mathrm{M}-\mathrm{H}$, fixed, $95 \% \mathrm{Cl})$ & $1.62(1.36,1.92)$ & 0 \\
\hline Dizziness $^{4-9}$ & 6 & 4,164 & Risk ratio $(\mathrm{M}-\mathrm{H}$, fixed, $95 \% \mathrm{Cl})$ & $2.74(2.06,3.65)$ & 7 \\
\hline Insomnia ${ }^{4-9}$ & 6 & 4,164 & Risk ratio $(\mathrm{M}-\mathrm{H}$, fixed, $95 \% \mathrm{Cl})$ & $1.59(1.25,2.02)$ & 0 \\
\hline
\end{tabular}

Abbreviations: $\mathrm{M}-\mathrm{H}$, Mantel-Haenszel; $\mathrm{Cl}$, confidence interval. 


\section{Disclosure}

The author reports no conflicts of interest in this communication.

\section{References}

1. Caixàs A, Albert L, Capel I, Rigla M. Naltrexone sustained-release/ bupropion sustained-release for the management of obesity: review of the data to date. Drug Des Devel Ther. 2014;8:1419-1427.

2. Gray LJ, Cooper N, Dunkley A, et al. A systematic review and mixed treatment comparison of pharmacological interventions for the treatment of obesity. Obes Rev. 2012;13(6):483-498.

3. James WP, Caterson ID, Coutinho W, et al; SCOUT Investigators. Effect of sibutramine on cardiovascular outcomes in overweight and obese subjects. N Engl J Med. 2010;363(10):905-917.

4. Hollander P, Gupta AK, Plodkowski R, et al; COR-Diabetes Study Group. Effects of naltrexone sustained-release/bupropion sustainedrelease combination therapy on body weight and glycemic parameters in overweight and obese patients with type 2 diabetes. Diabetes Care. 2013;36(12):4022-4029.

5. Apovian CM, Aronne L, Rubino D, et al; COR-II Study Group. A randomized, phase 3 trial of naltrexone SR/bupropion SR on weight and obesity-related risk factors (COR-II). Obesity (Silver Spring). 2013; 21(5):935-943.
6. Greenway FL, Dunayevich E, Tollefson G, et al; NB-201 Study Group. Comparison of combined bupropion and naltrexone therapy for obesity with monotherapy and placebo. J Clin Endocrinol Metab. 2009; 94(12):4898-4906.

7. Greenway FL, Fujioka K, Plodkowski RA, et al; COR-I Study Group. Effect of naltrexone plus bupropion on weight loss in overweight and obese adults (COR-I): a multicentre, randomised, double-blind, placebocontrolled, phase 3 trial. Lancet. 2010;376(9741):595-605.

8. Greenway FL, Whitehouse MJ, Guttadauria M, et al. Rational design of a combination medication for the treatment of obesity. Obesity (Silver Spring). 2009;17(1):30-39.

9. Wadden TA, Foreyt JP, Foster GD, et al. Weight loss with naltrexone SR/bupropion SR combination therapy as an adjunct to behavior modification: the COR-BMOD trial. Obesity (Silver Spring). 2011;19(1):110-120.

10. Higgins JPT, Green S, editors. Cochrane Handbook for Systematic Reviews of Interventions (Wiley Cochrane Series). Chichester, UK: Wiley-Blackwell; 2008.

11. Pereira TV, Horwitz RI, Ioannidis JP. Empirical evaluation of very large treatment effects of medical interventions. JAMA. 2012;308(16):1676-1684.

\section{Publish your work in this journal}

Drug Design, Development and Therapy is an international, peerreviewed open-access journal that spans the spectrum of drug design and development through to clinical applications. Clinical outcomes, patient safety, and programs for the development and effective, safe, and sustained use of medicines are a feature of the journal, which has also been accepted for indexing on PubMed Central. The manuscript management system is completely online and includes a very quick and fair peer-review system, which is all easy to use. Visit http://www.dovepress.com/testimonials.php to read real quotes from published authors.

Submit your manuscript here: http://www.dovepress.com/drug-design-development-and-therapy-journal 